\title{
Lack of Expression of Aminoacylase-1 in Small Cell Lung Cancer Evidence for Inactivation of Genes Encoded by Chromosome 3p
}

York E. Miller, John D. Minna, and Adi F. Gazdar

Department of Medicine, Veterans Administration Medical Center, Eleanor Roosevelt Institute for Cancer Research, University of Colorado Cancer Center, University of Colorado Health Sciences Center, Denver, Colorado 80220; and Navy Medical Oncology Branch, National Cancer Institute and Naval Hospital, Bethesda, Maryland 20814

\begin{abstract}
A deletion involving chromosome 3p (14-23) characteristically occurs in small cell lung cancer (SCLC). Reduction to homozygosity, rather than complete loss, is typically observed for genes in the deleted region. Lack of expression for genes encoded by this region, implying inactivation of all alleles, has not been previously described. We have examined the expression of aminoacylase-1 (ACY-1), encoded by chromosome 3p21, using both an electrophoretic activity assay and a monoclonal antibody-based ELISA. A variety of human tissues, including lung, brain, liver, kidney, heart, adrenal medulla, and erythrocytes have previously been tested for ACY-1 activity and antigen; all but erythrocytes are positive. Thus, ACY-1 is expressed in all nucleated human cells examined to date. ACY-1 was undetectable in a significant number of SCLC cell lines $(4 / 29)$ and tumors $(1 / 8)$, but not in non-small cell lung cancer (NSCLC) cell lines $(0 / 19)$ or tumors $(0 / 9)$, nor in a variety of other human cell lines $(0 / 15)$ or colon tumors $(0 / 8)$. In addition, reduced $(\sim 10 \%$ of normal) ACY-1 expression was common in SCLC cell lines (14/29) and tumors (3/8), but not in NSCLC cell lines $(1 / 19)$ or tumors $(0 / 9)$, nor in other human cell lines $(0 / 15)$ or colon tumors $(0 / 8)$. Thus, low or undetectable ACY-1 expression is highly specific for SCLC and occurs in both cell lines and tumor tissue. The finding of undetectable ACY-1 expression in SCLC supports the hypothesis that inactivation of all alleles of specific chromosome 3p genes occurs in SCLC in a fashion analogous to $R b$ gene inactivation in retinoblastoma, and suggests that the structural gene for ACY-1 may be closely linked to a putative SCLC tumor suppressor gene.
\end{abstract}

\section{Introduction}

Based on clinical and epidemiologic observations, Knudsen, and subsequently Comings, hypothesized that in the develop-

Portions of this work were presented to the annual meetings of the American Federation for Clinical Research, 1986, and the American Society of Human Genetics, 1987, and were published in abstract form in 1986 (Clin. Res. 34:568A) and 1987 (Am. J. Hum. Genet. 41:A32).

Address reprint requests to Dr. York E. Miller, Research 151, Veterans Administration Medical Center, 1055 Clermont St., Denver, CO 80220.

Received for publication 11 January 1989 and in revised form 10 March 1989.

The Journal of Clinical Investigation, Inc.

Volume 83, June 1989, 2120-2124 ment of specific neoplasms certain genes are inactivated $(1,2)$. In inherited forms of specific neoplasms this inactivation is due to a defective germ line allele with a somatic mutation affecting the remaining normal gene. In sporadic forms of these tumors two somatic mutations are hypothesized to have occurred. Cytogenetic observations of tumor-specific deletions, typically visibly affecting only one copy of a chromosome, have provided suggestive evidence for the location of such genes, termed tumor suppressor genes (3). In retinoblastoma, associated with a deletion of chromosome 13q14, further delineation of the tumor suppressor locus was provided by the discovery that the gene encoding the enzyme esterase $D$ is tightly linked to the $R b$ gene (4). The $R b$ gene has now been isolated and found to display abnormalities of expression at the mRNA and protein levels in retinoblastoma cell lines and tumors (5-8). Recently, frequent inactivation of the $R b$ gene has been described in both small cell lung cancer (SCLC) ${ }^{1}$ and breast cancer (9-11).

SCLC displays a characteristic loss of genetic material, usually in the form of a deletion, involving the short arm of chromosome 3 , detected both cytogenetically and by the molecular demonstration of loss of alleles (12-15). The dimensions of the deletion are variable, but the region $3 \mathrm{p} 21$ appears to be universally involved, as DNA probes for the $3 \mathrm{p} 21$ locus DNF 15S2 are reduced to homozygosity in all cases of unequivocal SCLC reported to date (13-15). However, complete inactivation of a chromosome 3p21 gene in SCLC has not previously been reported.

Aminoacylase-1 (ACY-1; $\mathrm{N}$-acylaminoacid aminohydrolase, EC 3.4.1.14) is a cytosolic enzyme widely distributed in mammalian tissues that catalyzes the hydrolysis of acylated amino acids into amino acids and acyl groups. The role of the enzyme in cellular physiology is unknown, but it has been postulated to function in the catabolism of amino-terminally acylated proteins (16). Because ACY-1 has been assigned to chromosome 3p21 $(17,18)$, we examined its expression in SCLC. ACY-1 is frequently not detectable in SCLC, but has been detectable in all other neoplasms and normal tissues (with the exception of erythrocytes) examined to date. Thus, ACY-1 inactivation is highly specific for SCLC. These findings support the dual inactivation of chromosome $3 \mathrm{p} 21$ genes in SCLC, suggest that the ACY-1 and SCLC tumor suppressor genes are closely linked, and may aid in the isolation of an SCLC tumor suppressor gene.

1. Abbreviations used in this paper: ACY-1, aminoacylase-1; LDH, lactate dehydrogenase; NSCLC, non-small cell lung cancer; SCLC, small cell lung cancer. 


\section{Methods}

Cell lines, culture, and preparation of samples. SCLC, non-small cell lung cancer (NSCLC), and other human cell lines were established and propagated as described (19).

Cell lines were harvested, washed twice in PBS (pH 7.4), resuspended in a volume of distilled water approximately equal to that of the cell pellet, and freeze-thawed three times. After centrifugation for 5 min in a high speed microfuge (model 5412; Eppendorf, Hamburg, West Germany) supernatants were removed and protein was determined and then frozen at $-70^{\circ} \mathrm{C}(20)$.

Tumor samples were obtained at autopsy or surgery, dissected free of obviously normal tissue, and stored at $-70^{\circ} \mathrm{C}$. Contaminating normal tissue was not formally quantitated, nor was such tissue microscopically removed. Before assay tumor samples were minced finely, suspended in an equal volume of distilled water, homogenized in a Dounce tissue grinder (Wheaton Scientific, Millville, NJ), and prepared as cell lines were. A crude preparation of human ACY-1 was purified from kidney as described (21).

Enzyme activity assays. The electrophoretic ACY-1 assay described by Quavi and Kit was performed (22). Initially, $5 \mu \mathrm{g}$ sample protein was applied per lane to a cellulose acetate gel before electrophoresis. Samples that failed to produce a distinct precipitate with $5 \mu \mathrm{g}$ protein were repeated with $50 \mu \mathrm{g}$ protein. ACY-1 activity was semiquantitatively graded as follows: positive, a distinct precipitate with 5 $\mu \mathrm{g}$ protein; reduced, no precipitate with $5 \mu \mathrm{g}$ protein but visible precipitate with $50 \mu \mathrm{g}$ protein; undetectable, no precipitate with $50 \mu \mathrm{g}$ protein. Lactate dehydrogenase (LDH) isozymes were performed as described, with $5 \mu \mathrm{g}$ protein loaded per lane (23).

ACY-1 ELISA. A previously described sandwich-type immunoassay using the anti-ACY-1 MAb 3D12 as capture antibody and rabbit anti-ACY-1 serum to detect immunoimmobilized ACY-1 was used for the measurement of ACY-1 antigen (21). Standard curves were constructed using varying dilutions of a partially purified ACY-1 preparation $(0.005,0.01,0.05,0.1,0.5,1.0 \mu \mathrm{g} /$ well). Unknown samples were initially assayed at concentrations of $0.05,0.1,0.5,1.0$, and 5.0 $\mu \mathrm{g} /$ well. If these failed to yield ODs that decreased in near linear fashion with increasing dilution, higher concentrations of 1.0, 5.0, 10, 20, and $40 \mu \mathrm{g} /$ well were tested (Fig. 1). The slope of linear portions of unknown sample determinations was normalized to linear portions of the standard curve, with results expressed as nanograms standard/microgram sample.

\section{Results}

Enzyme activity of cell lines and tumor samples. 29 SCLC cell lines were assayed for ACY-1 activity: 11 were positive, 13 reduced, and 5 undetectable (Table I). 34 human cell lines

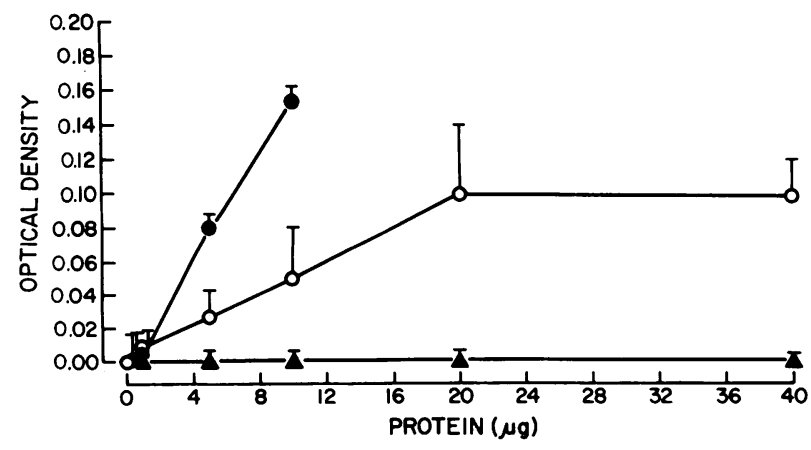

Figure 1. ACY-1 ELISA. Results of ACY-1 immunoassay for three SCLC cell lines, NCI H209 (•), NCI H417 (0), and NCI H1092 (^). Bars represent SD. For each sample, assay has a range in which OD is linear with protein. representing malignancies of various other histologic types were tested: 33 were positive, 1 reduced, and 0 undetectable. The differences in ACY-1 activity were significant when analyzed by Fisher's exact test, either compared in terms of undetectable $(P<0.02)$ or reduced plus undetectable $(P<0.001)$. SCLC cell lines have been divided into classic and variant subtypes based on the loss of neuroendocrine markers (24). All five SCLC cell lines with undetectable ACY-1 activity are of the classic subtype.

Because tumors can undergo additional phenotypic alterations after being established in culture as cell lines, we examined ACY-1 activity in tissue from eight SCLC tumors obtained either at autopsy or surgery, and in tissue from nine NSCLC and eight colon carcinomas obtained at surgery. Four SCLC tumors were positive, three reduced, and one undetectable; in none of the other tumors was ACY-1 reduced or undetectable $(P<0.01$, Fisher's exact test). The SCLC tumor that was $\mathrm{ACY}-1$ negative was a subcutaneous metastasis that was surgically removed, immediately frozen at $-70^{\circ} \mathrm{C}$, then assayed for ACY-1 activity within $1 \mathrm{wk}$, making ACY-1 degradation very unlikely in that particular sample (Fig. 2).

ACY -1 activity was stable in samples frozen for at least 6 mo and was not notably affected by freeze-thawing up to five times after initial preparation. However, to control for possible degradation of enzyme activity, all samples in which ACY-1 was undetectable or reduced were assayed for LDH isozymes encoded by nonlinked chromosomal loci by a similar semiquantitative electrophoretic assay. No diminution in LDH activity was observed (Figs. 2 and 3). To determine whether a soluble inhibitor might be responsible for the decreased ACY-1 activities seen in SCLC samples, equal amounts of ACY-1 negative and positive samples were mixed and assayed. No reduction in activity was apparent.

$A C Y-1$ ELISA. ACY-1 antigen was quantitated by ELISA in all 29 SCLC and in 24 other human cell lines (Table I). The quantitative ELISA results correlate well with the semiquantitative activity assay (Spearman's rank correlation, $r_{s}=0.794$; $P<0.001$ ) as would be expected if both are measuring the same enzyme. Three SCLC samples were negative by ELISA but had a small level of ACY-1 activity; one sample had no detectable activity but displayed small levels of ACY-1 antigen. Four SCLC cell lines (National Cancer Institute (NCI) H187, NCI H711, NCI H1008, and NCI H1092) lacked ACY-1 by both antigen and activity assays. ACY-1 content of SCLC cell lines was significantly less than that of NSCLC ( $P$ $<0.001)$ and other $(P<0.01)$ cell lines (Wilcoxon rank sum test).

Antigen was also quantitated in all tumor tissue samples (Fig. 4). The SCLC tumor sample that lacked detectable ACY-1 antigen also lacked detectable ACY-1 activity. ACY-1 content of SCLC tumor şamples was significantly less than that of NSCLC $(P<0.02)$ and colon $(P<0.001)$ tumors (Wilcoxon rank sum test).

\section{Discussion}

The deletion of chromosome $3 p$ (14-23) characteristic for SCLC has been confirmed on a cytogenetic and molecular basis by several groups (12-15). Cytogenetic analysis typically reveals at least one normal copy of chromosome 3 in SCLC isolates (12). Furthermore, molecular analyses have revealed that at least one copy of all genes examined to date encoded by 
Table I. ACY-1 Expression in Cell Lines

\begin{tabular}{|c|c|c|c|c|c|}
\hline SCLC & Activity & ELISA & NSCLC & Activity & ELISA \\
\hline & & ng standard//ug sample & & & ng standard/ug sample \\
\hline H209 & Positive & 23.7 & $\mathrm{H} 28$ & Positive & 88.7 \\
\hline H841 & Positive & 4.9 & H522 & Positive & 9.7 \\
\hline H82 & Positive & 13.7 & H358 & Positive & 28.7 \\
\hline H417 & Positive & 5.2 & H290 & Positive & 37.7 \\
\hline H446 & Positive & 8.1 & H441 & Positive & 25.7 \\
\hline H182 & Positive & 3.5 & H513 & Positive & 30.5 \\
\hline $\mathrm{H} 211$ & Positive & 22.7 & H727 & Positive & 163.7 \\
\hline H378 & Positive & 8.7 & H1155 & Positive & 6.2 \\
\hline H510 & Positive & 118.7 & $\mathrm{H} 762$ & Positive & 8.7 \\
\hline H889 & Positive & 6.8 & $\mathrm{H} 226$ & Positive & 14.5 \\
\hline H60 & Reduced & 2.4 & H520 & Positive & 4.7 \\
\hline H345 & Reduced & 0 & H596 & Positive & 36.7 \\
\hline H740 & Reduced & 0 & H647 & Positive & 9.3 \\
\hline H862 & Reduced & 3.7 & H661 & Positive & 9.3 \\
\hline $\mathrm{H} 774$ & Reduced & 3.7 & H1264 & Positive & 81.7 \\
\hline $\mathrm{H} 792$ & Reduced & 0 & H157 & Positive & 51.7 \\
\hline H128 & Reduced & 0.25 & $\mathrm{H} 125$ & Positive & 3.8 \\
\hline H69 & Reduced & 0.8 & A549 & Positive & ND \\
\hline H1062 & Reduced & 0 & H640 & Reduced & 0.7 \\
\hline H847 & Reduced & 0 & Other & & \\
\hline H1086 & Reduced & 0.2 & H548 (colon) & Positive & 83.7 \\
\hline H146 & Reduced & 0.7 & H1011 (neuroepithelioma) & Positive & 6.3 \\
\hline H1184 & Reduced & 2.7 & MKL-1 (Merkel cell) & Positive & 3.2 \\
\hline H962 & Reduced & 2.9 & BL-1 (lymphoblastoid) & Positive & 21.5 \\
\hline H930 & Undetectable & 1.2 & BL-2 (lymphoblastoid) & Positive & 127.7 \\
\hline H711 & Undetectable & 0 & BL-5 (lymphoblastoid) & Positive & 15.2 \\
\hline H187 & Undetectable & 0 & FAMC-180 (melanoma) & Positive & ND \\
\hline H1092 & Undetectable & 0 & HeLa (cervix) & Positive & ND \\
\hline \multirow[t]{7}{*}{ H1008 } & Undetectable & 0 & Hep G2 (hepatoma) & Positive & ND \\
\hline & & & HT 1080 (hepatic fibrosarcoma) & Positive & ND \\
\hline & & & U-937 (leukemia, monocytic) & Positive & ND \\
\hline & & & HL 60 (leukemia, monocytic) & Positive & ND \\
\hline & & & CEM (leukemia, T cell) & Positive & ND \\
\hline & & & K562 (erythroleukemia) & Positive & ND \\
\hline & & & Daudi (lymphoma, B cell) & Positive & ND \\
\hline
\end{tabular}

chromosome 3p is present in SCLC (13-15). Dual inactivation of genes encoded by chromosome $3 p$, analogous to the inactivation of the $R b$ gene in retinoblastoma, has not been demonstrated. Here we report that ACY-1, encoded by chromosome $3 p 21$, is frequently not detectable in SCLC samples either as an activity or an antigen. Because ACY-1 inactivation is not uni-

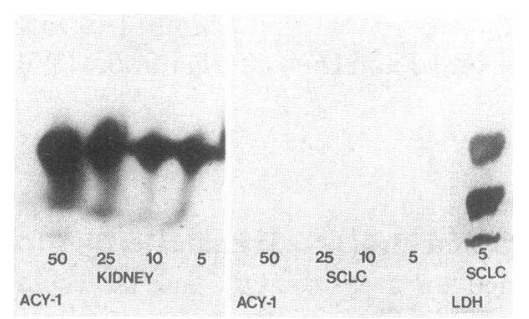

Figure 2. Enzyme activity assays for SCLC tumor and human kidney. Numbers represent micrograms of protein loaded per lane. Left, ACY-1 activity of a human kidney obtained at autopsy; middle, ACY-1 activity of the

SCLC tumor; right, LDH activity of the SCLC tumor. ACY-1 activity is not detectable in the tumor, although LDH is still expressed. Kidney is a positive control, demonstrating function of ACY-1 assay. versal in SCLC, it is unlikely to be an SCLC tumor suppressor gene. However, the locus of ACY-1 on chromosome 3p21 and the specificity of ACY-1 inactivation for SCLC suggests that ACY-1 may be closely linked to an SCLC tumor suppressor gene.

ACY-1 inactivation in SCLC is somewhat similar to esterase $D$ inactivation in retinoblastoma (4). Because ACY-1 does not exhibit polymorphism, as does esterase $\mathrm{D}$, loss of a single allele cannot be convincingly demonstrated, although it probably occurs. However, completely undetectable ACY-1 expression may point to a process of gene inactivation, either mutational or by DNA modification, affecting all copies of chromosome 3 in SCLC. Such a complete loss of expression has not been documented to involve esterase $D$ in retinoblastoma, although complete inactivation of the closely linked ( 350,000 bp) $R b$ gene does occur (25).

The two independent ACY-1 assays performed both detect ACY-1 in all other human cell lines and tumor samples tested. Previously, we have reported ACY-1 expression in human lung, brain, heart, adrenal medulla, kidney, and liver, but not 


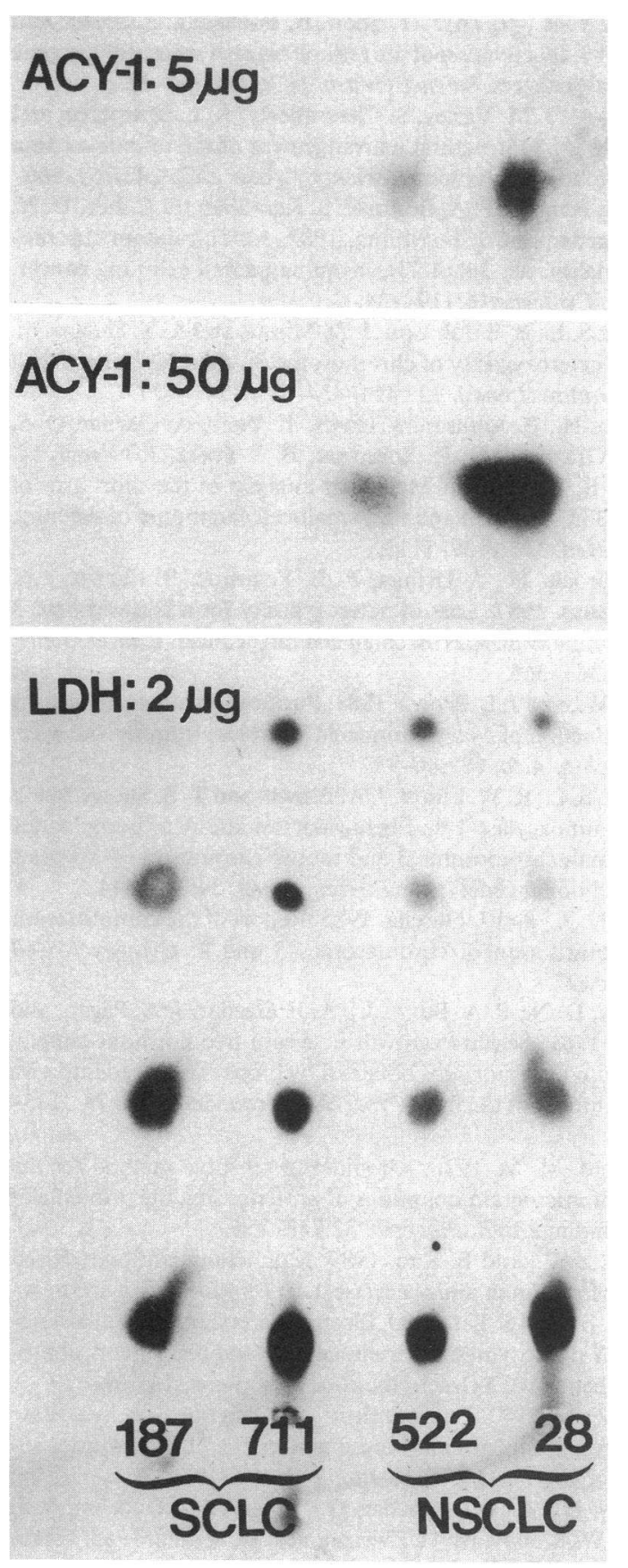

Figure 3. ACY-1 and LDH activities of cell lines, demonstrating selective absence of ACY-1 activity in certain SCLC lines. Full designation of cell lines includes the prefix NCI H. Similar results obtained with SCLC lines NCI H 1008 and NCI H 1092 are not included in figure.

in human erythrocytes (21). Other investigators have reported similar expression in rodent tissues $(26,27)$. Thus, ACY-1 is expressed in all tissues containing nucleated cells tested to date. Lack of expression of ACY-1 is therefore highly specific for, but not universal in, SCLC. It is, of course, possible that the SCLC samples in which ACY-1 is undetectable actually do express very low amounts of the enzyme. To examine the possibility that lack of expression might be due to a tendency for SCLC samples to autolyse, LDH isozymes have been tested

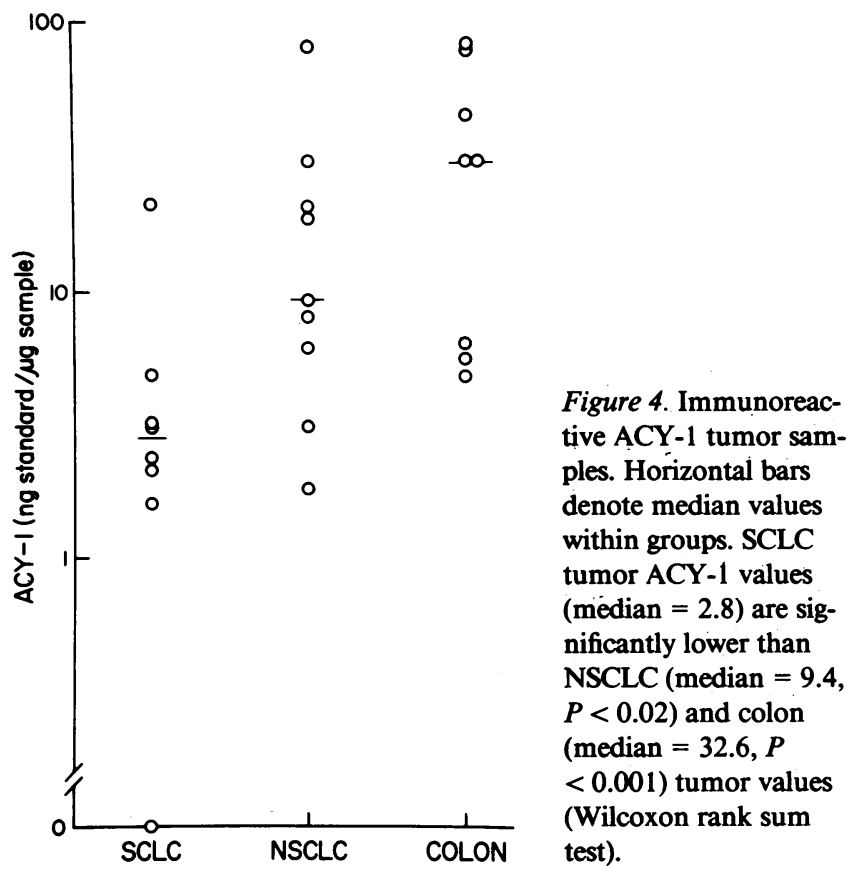

in all ACY-1 negative samples. All express LDH. Selective degradation of ACY-1 in SCLC samples is unlikely, as ACY-1 is an intrinsically stable enzyme, resistant to heating to $70^{\circ} \mathrm{C}$ and stable after several days of refrigeration $(16,28)$.

The majority of the SCLC samples we have tested have been prepared from SCLC cell lines. 4 of 29 such samples have undetectable ACY-1 by both activity and ELISA. One advantage of using cell lines is that there is no contamination by normal tissue. A potential problem, however, is that cell lines may undergo additional genetic changes as they are passaged in vitro. We believe that this is an unlikely explanation for loss of ACY-1 expression for two reasons: first, ACY-1 loss is not preferentially seen in cell lines established in the more distant past, and second, ACY-1 loss is not observed in any human cell lines other than SCLC. Because of these concerns, however, we have tested a number of SCLC tumors for ACY-1 expression. Unfortunately, quantitation of contamination by normal tissue is not available on these specimens. Three of eight SCLC tumors have reduced ACY-1 activity; approximately $1 / 10$ that observed in the NSCLC and colon tumors. This could represent either low ACY-1 activity in the tumor or no ACY-1 activity in tumor with residual activity being supplied by contaminating normal tissue. One SCLC tumor had undetectable ACY-1 activity and antigen. Thus, although the data are limited, these results demonstrate ACY-1 inactivation in at least one SCLC tumor, as well as cell lines.

We are currently able to investigate ACY-1 expression on an activity and antigenic basis only. Proof that ACY-1 inactivation is a mutational event will require the isolation of cDNA probes and the demonstration of deletions, rearrangements, or other mutations involving the ACY-1 gene. Expression of an abnormal size mRNA would also support a mutational basis for ACY-1 inactivation.

Low but detectable levels of ACY-1 expression also occur frequently in SCLC samples. We have isolated putative clonal cell lines from SCLC cultures expressing low ACY-1 and assayed their ACY-1 expression (data not shown). Although the 
number of clones examined is small, there has, to date, been no evidence for a mixed population of $A C Y-1$ positive and negative cells in the original lines. Many mechanisms could account for low ACY-1 expression in SCLC lines, including DNA modification or mutations involving promoter or enhancer regions.

The region deleted in SCLC is very large, $\sim 1-2 \%$ of the haploid human genome. Presumably, complete loss of all genes within such an extensive region would be lethal. By analogy to retinoblastoma, one or more tumor suppressor genes within this region may be completely inactivated. Our findings regarding ACY-1 expression are consistent with this dual inactivation hypothesis and may provide a valuable clue as to the locus of an SCLC tumor suppressor gene linked to ACY-1. Furthermore, if a significant proportion of SCLC tumors do not express ACY-1, this biochemical defect might allow the development of chemotherapeutic agents with selective toxicity for those tumors.

\section{Acknowledgmerits}

We thank B. Kao for expert technical assistance, E. Russell and H. Oie for culture and sample preparation, and R. Kight for manuscript preparation.

This work was supported by a grant from the Milheim Foundation and Merit Review and Clinical Investigator Career Development Awards from the Veterans Administration. This is contribution number 809 from the Eleanor Roosevelt Institute for Cancer Research.

\section{References}

1. Knudsen, A. G. 1971. Mutation and cancer: statistical study of retinoblastoma. Proc. Natl. Acad. Sci. USA. 68:820-823.

2. Comings, D. E. 1973. A general theory of carcinogenesis. Proc. Natl. Acad. Sci. USA. 70:3324-3328.

3. Klein, G. 1987. The approaching era of the tumor suppressor genes. Science (Wash. DC). 238:1539-1545.

4. Sparkes, R. S., M. C. Sparkes, M. G. Wilson, J. W. Towner, W. Benedict, A. L. Murphree, and J. S. Yunis. 1980. Regional assignment of genes for human esterase D and retinoblastoma to chromosome band 13q14. Science (Wash. DC). 208:1042-1044.

5. Friend, S.H., R. Bernards, S. Rogelj, R. A. Weinberg, J. M. Rapaport, D. M. Albert, and T. P. Dryja. 1986. A human DNA segment with properties of the gene that predisposes to retinoblastoma and osteosarcoma. Nature (Lond.). 323:643-646.

6. Lee, W.-H., R. Bookstein, F. Hong, L.-J. Young, J.-Y. Shew, and E. Y.-H. Lee. 1987. Human retinoblastoma susceptibility gene: cloning, identification and sequence. Science (Wash. DC). 235:1394-1399.

7. Fung, Y.-K. T., A. L. Murphree, A. T'Ang, J. Qian, S. H. Hinrichs, and W. F. Benedict. 1987. Structural evidence for the authenticity of the human retinoblastoma gene. Science (Wash. DC). 236:1657-1661.

8. Lee, W.-H., J.-Y. Shew, F. Hong, T. W. Sery, L. Donoso, L.-J. Young, R. Bookstein, and E. Y.-H. Lee. 1987. The retinoblastoma susceptibility gene encodes a nuclear phosphoprotein associated with DNA binding activity. Nature (Lond.). 329:642-645.

9. Harbour, J. W., S.-L. Lai, J. Whang-Peng, A. F. Gazdar, J. D. Minna, and F. J. Kaye. 1988. Abnormalities in the structure and expression of the human retinoblastoma gene in SCLC. Science (Wash. DC). 241:353-357.
10. Lee, E. Y.-H., H. To, J.-Y. Shew, R. Bookstein, P. Scully, and W.-H. Lee. 1988. Inactivation of the retinoblastoma susceptibility gene in human breast cancers. Science (Wash. DC). 241:218-221.

11. T'Ang, A., J. M. Varley, S. Chakraborty, A. L. Murphree, and Y.-K. T. Fung. 1988. Structural rearrangement of the retinoblastoma gene in human breast carcinoma. Science (Wash. DC). 242:263-266.

12. Whang-Peng, J., P. A. Bunn, C. S. Kao-Shan, E. C. Lee, D. N. Carney, A. Gazdar, and J. D. Minna. 1982. A non-random chromosomal abnormality, del 3p(14-23), in human small cell lung cancer. Cancer Genet. Cytogenet. 6:119-134.

13. Naylor, S. L., B. E. Johnson, J. D. Minna, and A. Y. Sakaguchi. 1987. Loss of heterozygosity of chromosome 3p markers in small cell lung cancer. Nature (Lond.). 329:451-454.

14. Brauch, H., B. Johnson, J. Hovis, T. Yano, A. Gazdar, O. S. Pettengill, S. Graziano, G. D. Sorenson, B. J. Poesz, J. Minna, M. Linehan, and B. Zbar. 1987. Molecular analysis of the short arm of chromosome 3 in small-cell and non-small-cell carcinoma of the lung. New Engl. J. Med. 317:1109-1113.

15. Mooibroek, H., J. Osinga, P. E. Postmus, B. Carritt, and C. H. C. M. Buys. 1987. Loss of heterozygosity for a chromosome 3 sequence presumably at 3p21 in small cell lung cancer. Cancer Genet. Cytogenet. 27:361-365.

16. Gade, W., and J. L. Brown. 1981. Purification, characterization and possible function of $\mathrm{N}$-acylaminoacid hydrolase from bovine liver. Biochem. Biophys. Acta. 662:86-93.

17. Naylor, S. L., R. W. Elliott, J. A. Brown, and T. B. Shows. 1982. Mapping of aminoacylase- 1 and beta-galactosidase-A to homologous regions of human chromosome 3 and mouse chromosome 9 suggests location of additional genes. Am. J. Hum. Genet. 34:235-244.

18. Kidd, K. K., and J. Gusella. 1985. Report of the committee on the genetic constitution of chromosomes 3 and 4. Cytogenet. Cell Genet. 40:107-127.

19. Carney, D. N., P. A. Bunn, Jr., A. F. Gazdar, J. A. Pagan, and J. D. Minna. 1981. Selective growth in serum-free hormone-supplemented medium of tumor cells obtained by biopsy from patients with small cell carcinoma of the lung. Proc. Natl. Acad. Sci. USA. 78:31853189.

20. Bradford, M. M. 1976. A rapid and sensitive method for the quantitation of microgram quantities of protein using the principle of protein-dye binding. Anal. Biochem. 72:248-254.

21. Miller, Y. E., and B. Kao. 1989. Monoclonal antibody based immunoassay for human aminoacylase-1. J. Immunoassay. In press.

22. Quavi, H., and S. Kit. 1980. Electrophoretic patterns of aminoacylase-1 (ACY-1) isozymes in vertebrate cells and histochemical procedure for detecting ACY-1 activity. Biochem. Genet. 18:669-679.

23. Khan, P. M. 1971. Enzyme electrophoresis on cellulose acetate gel: zymogram patterns in man-mouse and man-Chinese hamster somatic cell hybrids. Arch. Biochem. Biophys. 145:470-483.

24. Carney, D. N., A. F. Gazdar, G. Bepler, J. G. Guccion, P. J. Marangos, T. W. Moody, M. H. Zweig, and J. D. Minna. 1985. Establishment and identification of small cell lung cancer cell lines having classic and variant features. Cancer Res. 45:2913-2923.

25. Lee, W.-H., R. Bookstein, W. Wheatley, W. F. Benedict, and E. Y.-H. P. Lee. 1987. A null allele of esterase $D$ is a marker for genetic events in retinoblastoma. Hum. Genet. 76:33-36.

26. Endo, Y. 1978. $N$-acyl-L-aromatic amino acid deacylase in animal tissues. Biochem. Biophys. Acta. 523:207-214.

27. Naylor, S. L., T. B. Shows, and R. J. Klebe. 1979. Bioautographic visualization of aminoacylase-1: assignment of the structural gene ACY-1 to chromosome 3 in man. Somatic Cell Genet. 5:11-21.

28. Szajani, B: 1980. A new method for the isolation of aminoacylase-1 from mammalian kidneys. Acta Biochim. Biophys. Acad. Sci. Hung. 15:287-293. 